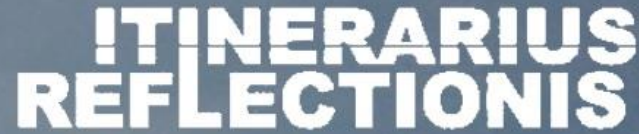

Revista Eletrônica de Graduação e Pós-Graduação em Educaçäo

\section{As Literaturas de Língua Inglesa como Ferramenta para Instigar a Aprendizagem de Inglês no Ensino Médio a partir da Identificação Social e Cultural}

\author{
Isabel Cristina Rodrigues Ferreira ${ }^{1}$ \\ Camila da Silva Gomes ${ }^{2}$
}

\begin{abstract}
Resumo: O presente artigo busca discutir a relevância do texto literário nas aulas de língua inglesa, atentando-se para um trabalho que visa a identificação social e cultural dos aprendizes com a obra. Nesse sentido, o corpus formado pelo poema "The Burglar of Babylon" (1965), da poeta estadunidense Elizabeth Bishop, foi utilizado no estágio supervisionado do curso de licenciatura em Letras Português/Inglês e suas Literaturas, cujo foco se pautou na utilização das literaturas de língua inglesa. Os objetivos que permeiam o artigo são os de despertar o interesse pela leitura literária de textos provindos de países e culturas anglófonas; promover a interação e a identificação cultural/social entre o texto e o sujeito; instigar o desejo do aluno acerca das literaturas de língua inglesa e, possivelmente, gerar interesse pela aprendizagem da língua. A metodologia adotada acompanha as etapas das aulas lecionadas, priorizando uma análise detalhada de todos os momentos. Inicia-se a análise a partir do momento de recepção da obra, seguindo até o momento de produção feita pelos próprios alunos. A pesquisa comprova a relevância de se explorar o texto literário em língua inglesa como ferramenta que fomenta o interesse dos aprendizes, aliando o interesse pela leitura literária e pela língua cuja obra foi escrita.
\end{abstract}

Palavras-chave: Literatura. Língua inglesa. Letramento literário. Diálogo intercultural.

\section{Literatures of the English Speaking World as a Tool to Instigate English Learning in High School from Social and Cultural Identification}

\begin{abstract}
This article seeks to discuss the relevance of the literary text in the English language classes, paying attention to a work that aims at the social and cultural identification of learners with a literary work. In this sense, the corpus formed by the poem "The Burglar of Babylon" (1965), by the American poet Elizabeth Bishop, was used in the teaching internship in the undergraduate course in Languages (Portuguese and English) and their Literatures, whose focus was based on the use of English-language literatures. The objectives that permeate the article are to arouse interest in reading literary texts from English-speaking countries and cultures; promote interaction and cultural / social identification between the text and the subject; instigate the student's desire for English language literature and, possibly, generate interest in language learning. The adopted methodology follows the steps of the classes taught, prioritizing a detailed analysis of all steps. The analysis begins from the moment of receipt of the work, following until the moment of production made by the students
\end{abstract}

\footnotetext{
${ }^{1}$ Doutora e Master of Arts in Romance Languages pela University of North Carolina at Chapel Hill. Possui Bacharelado em Matemática pela Universidade Federal de Minas Gerais, Licenciatura em Letras - Inglês pela Universidade Federal de Minas Gerais. Atualmente é professora adjunta em Língua Inglesa e suas Literaturas da Universidade Federal de Lavras. Tem experiência na área de Letras, com ênfase em Língua Inglesa e suas Literaturas, Português como Língua Estrangeira e Literaturas em Língua Portuguesa. Pesquisa principalmente as seguintes temáticas: aspectos sociais, raciais, culturais e de gênero na literatura e tem interesse pela computação ao serviço das humanidades. E-mail: isabelferreira@ufla.br.

${ }^{2}$ Mestranda em Letras pela Universidade Federal de São João Del-Rei (UFSJ) na linha de discurso. Graduada no curso de Letras Português/Inglês presencial pela Universidade Federal de Lavras. Desenvolveu pesquisa junto ao Neadi/UFLA (Núcleo de Estudos em Análise do Discurso- AD) abordando a Análise do Discurso de vertente francesa (Pêcheux), tendo como foco o discurso feminino. Atuou como bolsista PIBIC/UFLA no projeto Referenciação e Discurso: Análise de textos dissertativos-argumentativos. Foi professora de Português para estrangeiros no Núcleo de Línguas (NUCLi) da UFLA. E-mail: milagomesletras@gmail.com.
} 


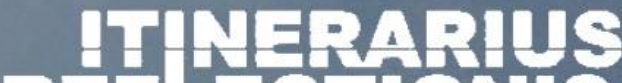 REFLETIONIS}

Revista Eletrônica de Graduação e Pós-Graduação em Educaçäo

themselves. The research proves the relevance of exploring the literary text in English as a tool that fosters the interest of learners, combining the interest in literary reading and the language whose work was written.

Keywords: Literature. English. Literary literacy. Intercultural dialogue.

\section{INTRODUÇÃO}

O ensino e a aprendizagem de uma língua estrangeira nas escolas, como é o caso do inglês, não usufrui, em geral, de uma carga horária ampla ou suficientemente adequada aos propósitos pedagógicos de ensino, podendo afetar a integralidade de ensino proposto nos documentos e diretrizes educacionais nacionais. A Base Nacional Comum Curricular (BNCC) prevê que no ensino médio, o ensino de língua inglesa deve, entre outras coisas, abrir “possibilidades de aproximação e integração com grupos multilíngues e multiculturais no mundo global - contanto que estes saibam se comunicar em inglês -, com diferentes repertórios linguístico-culturais" (BRASIL, 2017, p. 476). Uma forma de cumprir tal objetivo e ampliar o repertório linguístico-cultural dos aprendizes é por meio da interação destes com diferentes gêneros textuais, incluindo os gêneros literários de língua inglesa. As literaturas de língua inglesa, no entanto, ocupam pouco ou quase nenhum espaço nas aulas de inglês.

Este artigo é fruto da experiência vivenciada no último estágio supervisionado de língua inglesa do curso de Licenciatura em Letras Português/Inglês e suas Literaturas, direcionando às literaturas de língua inglesa no ensino médio com o objetivo de refletir sobre o uso do texto literário como ferramenta de aproximação do aprendiz à cultura anglófona, muitas vezes vista como distante e inatingível, e de interação social e cultural entre o texto e o sujeito. Escolhemos o poema "The Burglar of Babylon" (1965) escrito por Elizabeth Bishop (1911-1979), poeta estadunidense, por proporcionar aos estudantes a possibilidade de descobrir a visão de uma escritora anglófona sobre o Brasil, onde viveu entre 1952 e 1966. Bishop viajou bastante por diversas partes do mundo ao longo da vida. Em 1951, numa viagem para a Terra do Fogo, desembarcou em Santos para uma temporada de duas semanas. Foi para o Rio de Janeiro visitar amigos e, por intoxicação alimentar, não pode continuar a viagem. Durante o tempo que ficou no Brasil, viajou bastante pelo país, morou em Petrópolis e passou temporadas em Ouro Preto. Depois de retornar para os Estados Unidos da América, ela voltou diversas vezes a Ouro Preto até 1974. 


\section{ITHepapins REFLETIONIS}

Revista Eletrônica de Graduação e Pós-Graduação em Educaçäo

Diante do objetivo exposto, embasamos a nossa pesquisa principalmente na importância do texto literário nas aulas de inglês explicitada por Wasikiewicz-Firlei e ampliada por Cosson e Corchs. Antes de apresentar a fundamentação teórica, delimitamos o corpus da pesquisa bem como os mecanismos usados no seu contexto. Depois, discorremos sobre cada uma das etapas da atividade executada, especialmente a relacionada à produção escrita dos aprendizes, como forma de diálogo com o texto literário. Finalmente, refletimos sobre os resultados da atividade, apoiando nossa análise na perspectiva teórica abordada, com o objetivo de apresentar uma ferramenta que pode aproximar o universo do aprendiz ao da cultura anglófona, como forma de buscar gerar interesse dos aprendizes pela aprendizagem da língua inglesa.

\section{METODOLOGIA}

A pesquisa foi desenvolvida com vinte e cinco alunos do segundo ano do ensino médio em uma escola da rede pública da cidade de Lavras, localizada no sul de Minas Gerais, na aula de língua inglesa. O tempo disposto para a realização das etapas foi de uma hora e quarenta minutos, equivalente a duas aulas. A abordagem utilizada tem base qualitativa, porque explora informações mais subjetivas e não-quantificáveis e estimula a liberdade e a opinião livre do sujeito, como explica Lakatos e Marconi (1991). Buscamos, nesse sentido, oportunizar os alunos envolvidos na atividade a ter contato com o texto literário "The Burglar of Babylon" (1965) escrito por Elizabeth Bishop e a estabelecer diálogos entre os sujeitos e o texto expressando livremente suas ideias sobre a leitura do texto.

Cabe mencionar que este foi o primeiro contato que os aprendizes tiveram com um texto literário de língua inglesa ou de língua não materna. Assim, antes de começar o desenvolvimento da atividade, fizemos uma pergunta diagnóstica genérica para saber se gostavam de literatura, uma vez que não conheciam muitas obras de língua inglesa. Alguns fatores contribuem para tal desconhecimento, incluindo o fato de a escola possuir apenas três livros no acervo da biblioteca e a ausência ou presença insuficiente das literaturas de língua inglesa nos livros didáticos adotados. A resposta negativa à pergunta foi unânime. Como justificativa para o desinteresse, eles consideram os gêneros literários de difícil compreensão e, por isso, chatos e irrelevantes para suas vidas. Portanto, como já postulado anteriormente, a motivação para essa pesquisa foi a de, inicialmente, incentivar a leitura e o descobrimento do 


\section{ITHepapins REFLETIONIS}

Revista Eletrônica de Graduação e Pós-Graduação em Educaçäo

prazer pela literatura e, posteriormente, de abrir caminho para o desejo pela aprendizagem da língua inglesa.

Depois do diagnóstico, começamos a executar as etapas com os estudantes organizados em formatos diferentes, dependendo da etapa (duplas ou trios, individualmente e em grupo) que serão detalhadas na seção quatro do presente artigo. Cabe ressaltar que a abordagem foi bastante superficial mas, poderia ser melhor explorada e aprofundada em aulas subsequentes, na forma de uma sequência didática, caso tivéssemos mais tempo. A proposta visa uma interação aberta e livre com a obra, como detalharemos melhor na seção quatro. A partir da delimitação do objeto e dos mecanismos da pesquisa, a seção seguinte apresenta a importância do ensino de Literaturas de Língua Inglesa na aula de inglês no ensino médio como forma de abordar aspectos culturais, interculturais, sociais e letramento literário.

\section{ASPECTOS CULTURAIS, INTERCULTURAIS, SOCIAIS E LETRAMENTO LITERÁRIO}

Antes de começarmos a refletir sobre algumas abordagens do texto literário na sala de aula, vale lembrar que este gênero textual atende alguns objetivos que o ensino de língua inglesa deve alcançar. Nessa perspectiva, a abordagem da língua inglesa no ensino médio, de acordo com a BNCC (2017), deve dar continuidade ao que se priorizou nos anos finais do ensino fundamental, isto é, uma visão "intercultural e desterritorializada" (BRASIL, 2017, p. 484) e enfatizar os multiletramentos, possibilitando, dessa maneira, uma visão híbrida da língua estrangeira. Assim, o uso da literatura pode ser um dos caminhos possíveis e fecundos para o ensino intercultural e para as reflexões críticas. Nessa perspectiva, Zyngier (2011) aponta para a importância do uso da literatura para desenvolver a interpretação crítica do leitor e a formação do posicionamento crítico dos aprendizes, capacitando-os para "questionar e buscar entender as relações entre o ser humano, a sociedade e a linguagem" (ZYNGIER, 2011, p. 14). Corroborando com essa ideia, o documento estabelece e promove

\footnotetext{
expandir os repertórios linguísticos, multissemióticos e culturais dos estudantes, possibilitando o desenvolvimento de maior consciência e reflexão críticas das funções e usos do inglês na sociedade contemporânea - permitindo, por exemplo, problematizar com maior criticidade os motivos pelos quais ela se tornou uma língua de uso global. (BRASIL, 2017, p. 485)
}

Esse material, além de outros mecanismos de ensino, pode servir como ferramenta propulsora do interesse em aprender uma língua estrangeira. Bozza e Calixto (2013), citando 


\title{
ITHerapuns REFLETIONIS
}

Revista Eletrônica de Graduação e Pós-Graduação em Educaçäo

Duff e Malley (2003), “defendem o uso do texto literário como um recurso importante para estimular as atividades com a língua, ao considerarem que literatura é material autêntico, uma vez que não é produzida artificialmente para fins pedagógicos" (BOZZA; CALIXTO, 2013, p. 7). Collie e Slater (2001) enfatizam o enriquecimento cultural e linguístico criados pelo texto literário no contexto do ensino de língua estrangeira, corroborando com o posicionamento tomado por Duff e Malley. O texto literário, seja ele um poema, um conto, uma novela, um romance, ou qualquer outro gênero literário, possibilita reflexões e questionamentos sobre aspectos da cultura e da sociedade ao qual se insere. Ademais, ele também possibilita um intercâmbio cultural, assumindo um caráter de ligação entre culturas, tanto no que diz respeito às diferenças entre as sociedades, quanto no que tange às suas similaridades, mesmo que o leitor não seja proficiente na língua de origem.

Assim, por ter um caráter universal, a literatura vai ao encontro do sujeito leitor, impactando-o de alguma forma, principalmente em uma formação mais completa e intercultural. Wąsikiewicz-Firlej (2012) postula que

\begin{abstract}
Um dos principais argumentos para se introduzir textos literários nas aulas de língua estrangeira e na educação intercultural está no fato de que obras literárias permitem ao leitor observar o mundo a partir de perspectivas múltiplas e valorizar a diversidade da percepção individual. $\mathrm{O}$ poder da literatura reside na sua capacidade única de envolver profundamente o leitor tanto em nível cognitivo quanto emocional. (WASIKIEWICZ-FIRLEI, 2012, p. 3 - Tradução nossa) ${ }^{3}$
\end{abstract}

A autora observa que o contato com os textos literários propicia múltiplas experiências para os sujeitos, entre elas a reflexão acerca de diferentes perspectivas de observação do mundo e os direciona para um letramento literário. De acordo com Cosson (2014), o letramento literário implica no

processo de apropriação da literatura enquanto linguagem. Para entendermos melhor essa definição sintética, é preciso que tenhamos bem claros os seus termos. Primeiro, o processo, que é a ideia de ato contínuo, de algo que está em movimento, que não se fecha. Com isso, precisamos entender que o letramento literário começa com as cantigas de ninar e continua por toda nossa vida a cada romance lido, a cada novela ou filme assistido. Depois, que é um processo de apropriação, ou seja, refere-se ao ato de tomar algo para si, de fazer alguma coisa se tornar própria, de fazê-la pertencer à pessoa, de internalizar ao ponto daquela coisa ser sua. É isso que sentimos quando lemos um poema e ele nos dá palavras para dizer o que não conseguíamos expressar antes. (COSSON, 2014)

\footnotetext{
${ }^{3}$ One of the main arguments for incorporating literary texts within the second language classroom and inter cultural education is concerned with the fact that works of literature enable the reader to observe the world from multifarious perspectives and cherish the diversity of individual perception. The power of literature lies in its unique ability to deeply involve the reader both at a cognitive, as well as emotional level. (WASIKIEWICZFIRLEI, 2012, p. 3)
} 


\section{MTIFARIUS REFLETIONIS}

Revista Eletrônica de Graduação e Pós-Graduação em Educaçäo

O letramento literário, sob esta perspectiva, pressupõe trabalhos que conduzam os leitores/alunos a se familiarizarem com as obras literárias. Desta forma, cabe ao professor possibilitar o acesso a uma diversidade de obras e estimular o diálogo delas com os leitores. De acordo com Lazar (2009), ao selecionar os textos literários para uma atividade, o professor deve considerar as necessidades, motivações, interesses e nível linguístico dos aprendizes. Portanto, o texto literário é um instrumento fundamental para envolver mental e emocionalmente os alunos e transportá-los para outros contextos que os levem a mudanças marcantes. Assim, "cabe ao professor saber introduzir os temas de forma que não se deixe perder a validade das obras, devido à grande importância do contato com a outra cultura" (SILVA, 2016, p. 202). Nesse diapasão, versa Corchs (2006) que

a ingressão do aluno em uma outra realidade de aprendizado traz benefícios não só culturais como também linguísticos. O aluno, ao conhecer novos mundos e outras formas de viver, pensar e agir pode expor os seus pontos de vista através de atividades orais e/ou escritas. (CORCHS, 2006, p. 18)

Ainda segundo Corchs (2006), "tais textos proporcionam ao aluno um contexto e uma linguagem que despertam o interesse em descobrir mais sobre determinada cultura ou povo e podem confrontá-la com aspectos de sua própria cultura" (CORCHS, 2006, p. 23). Sendo assim, os alunos se apropriam de benefícios linguísticos e podem utilizá-los para expor a sua própria realidade, percebendo, dessa forma, uma ligação entre a língua inglesa e os contextos aos quais estão inseridos, criando pontes de identificação da realidade social e cultural que conhecem.

É possível considerar que a literatura, trabalhada inicialmente para que o aluno se reconheça no texto, contrastando os elementos sócio culturais presentes e refletindo sobre diferentes temas propostos no texto a partir de uma outra visão proveniente de sujeitos de culturas distintas da sua, se torne um ponto propulsor para incentivar o desejo pela aprendizagem da língua inglesa. Nesse sentido, a interrelação que surge a partir dessa reflexão favorece o que pode ser chamado de abordagem intercultural. Segundo França e Santos (2008) citando Kramcsh (2004), um dos aspectos da abordagem intercultural é o de se pensar

no estabelecimento de uma esfera de interculturalidade, e isso é basicamente diferente de transferência de informação entre culturas. Esse processo envolve uma reflexão tanto da cultura nativa (C1) como da cultura-alvo (C2). (FRANÇA; SANTOS, 2008, p. 86) 


\section{ITHepapins REFLECTIONIS}

Revista Eletrônica de Graduação e Pós-Graduação em Educaçäo

Sendo assim, depreende-se que na abordagem intercultural, no contexto escolar, as atividades propostas e mediadas pelo professor consigam direcionar o aluno a estabelecer um diálogo entre as culturas, refletindo sobre ele.

Quando associado ao aspecto cultural, explora-se também as nuances linguísticas, possibilitando o desenvolvimento de várias habilidades e o entendimento de estruturas da língua. A produção escrita, por exemplo, equivale a uma das inúmeras possibilidades de atividades que podem contribuir para o letramento literário do leitor. Souza e Cosson (2011) asseguram a importância da prática da escrita no letramento literário quando afirmam que ela

\footnotetext{
significa bem mais do que o saber ler e escrever. Ele responde também pelos conhecimentos que veiculamos pela escrita, pelos modos como usamos a escrita para nos comunicar e nos relacionar com as outras pessoas, pela maneira como a escrita é usada para dizer e dar forma ao mundo, tudo isso de maneira bem específica. (SOUZA; COSSON, 2011, p. 102)
}

A seção seguinte discorre sobre as etapas da atividade proposta pelas autoras do presente trabalho que visou estabelecer esse diálogo intercultural entre os alunos do segundo ano do ensino médio e o eu lírico do poema "The Burglar of Babylon”, de Elizabeth Bishop, bem como a análise de algumas das produções escritas elaboradas pelos aprendizes em sala de aula. Dessa forma, a atividade trouxe a oportunidade de refletir sobre o olhar de um sujeito proveniente de outro país, portanto de uma cultura diferente da que eles conhecem, sobre aspectos sociais e culturais com os quais eles estão familiarizados, uma vez que o poema tem como cenário a Babilônia, comunidade situada na zona sul do Rio de janeiro. De acordo com o que expõe Souza e Cosson (2011),

O conhecimento prévio é considerado por vários autores como a estratégia "guardachuva", pois a todo momento o leitor ativa conhecimentos que já possui com relação ao que está sendo lido. Assim, antes de ler, as crianças geralmente acionam conhecimentos prévios que podem estar relacionados às ideias do texto. A atividade de acionar essas informações interfere diretamente na compreensão durante a leitura. (SOUZA; COSSON, 2011, p. 104)

Além disso, pensar no letramento literário dentro da sala de aula de literaturas de língua inglesa é auxiliar na criação de um ambiente no qual se aproveite todas as potencialidades e conhecimentos dos alunos. 


\section{ITHepapins REFLECTIONIS}

Revista Eletrônica de Graduação e Pós-Graduação em Educaçäo

4 ETAPAS DA ATIVIDADE DO POEMA "THE BURGLAR OF BABYLON", DE ELIZABETH BISHOP

Os vinte e cinco alunos participantes das etapas da atividade propostas em uma sala de aula do segundo ano do ensino médio não conheciam o poema escolhido, "The Burglar of Babylon”, de Elizabeth Bishop. Como explicitado anteriormente, os estudantes expressaram uma rejeição inicial ao gênero literário, mas não recuamos e desenvolvemos as etapas, como planejado, em duas aulas. Assim, estabelecemos as seguintes etapas: i) informações sobre a autora e o contexto de produção do poema; ii) leitura, em voz alta, do poema no original e entendimento geral; iii) leitura da tradução do texto em português e discussão mais aprofundada sobre a temática escolhida; e iv) produção textual, em língua portuguesa, da continuação do poema, como forma de dialogar com o texto criado por Elizabeth Bishop.

Na etapa i), os alunos tiveram acesso a dados bibliográficos da poeta Elizabeth Bishop para que compreendessem o por quê de alguns dos poemas de Bishop terem sido escritos no e sobre o Brasil bem como a curiosidades a respeito da autora e da obra. À vista disso, eles discutiram aspectos que conheciam sobre o morro da Babilônia, comunidade localizada na zona sul do Rio de Janeiro. Essa etapa foi fundamental para aliviar a tensão dos alunos para a etapa seguinte, porque o conhecimento prévio deles já havia sido ativado assim como algumas dúvidas sobre a poeta ou o contexto haviam sido sanadas. Dessa forma, eles se sentiram mais confortáveis e preparados. O êxito da etapa, portanto, está na maneira escolhida para engajar os alunos no desejo inicial pela leitura, diminuindo a falta de interesse e para mostrar o conhecimento que tinham sobre o contexto do poema, maior do que eles imaginavam.

Depois de ativar o conhecimento prévio dos alunos, seguimos para a etapa ii) que consistiu na leitura pausada em língua inglesa do poema "The Burglar of Babylon”. Os alunos foram distribuídos em duplas ou trios e receberam a cópia do poema para que alguns aspectos linguísticos pudessem ser abordados. Depois da leitura, os alunos levantaram algumas hipóteses, se ancorando no que compreenderam do poema e na etapa anterior, que permitiu maior confiança para inferências. Observa-se aqui a importância do trabalho do professor como facilitador e mediador do processo de ensino e aprendizagem e do letramento literário. Nesse sentido, alguns deles fizeram as seguintes colocações: a) Micuçu é o ladrão da Babilônia, portanto, o poema conta sua história; b) Micuçu é foragido e está sendo procurado 


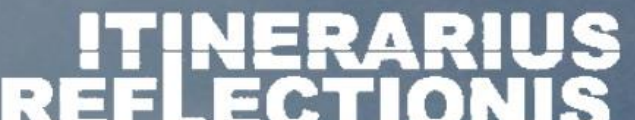 \\ REFLECTIONIS}

Revista Eletrônica de Graduação e Pós-Graduação em Educaçäo

pela polícia; c) o ladrão da Babilônia se despede da tia, pois sabe que vai morrer; e d) Micuçu morre e os ricos ficam aliviados com a sua execução. Os elementos captados inicialmente pelos alunos consistem no enredo principal do poema, ou seja, mesmo com o texto em inglês, os principais aspectos do poema foram identificados, propiciando, assim, autoconfiança e interesse para as próximas etapas da atividade. A leitura em língua inglesa atendeu às expectativas desejadas para a etapa. Além do que foi apresentado, durante esta etapa, poderíamos ter explorado os aspectos linguísticos, mesmo que muito brevemente. Contudo, não foi possível, visto que os alunos desejavam comentar sobre o texto literário e relacioná-lo às suas próprias experiências.

A etapa iii) visa discutir mais profundamente o poema. Para tal, optou-se por fazer uma nova leitura, só que do texto traduzido para língua portuguesa. Os alunos receberam o novo texto e discutiram em grupo novas descobertas: a) Micuçu se esconde na mata após despedir de sua tia; b) Micuçu é condenado a noventa anos de prisão; c) os ricos, que vivem em coberturas na zona sul, utilizam binóculos para acompanhar a busca por Micuçu; d) um soldado é morto pelo colega e há uma tentativa de encerrar as buscas; e) o dia amanhece e Micuçu vê, enquanto se esconde na mata, banhistas bem dormidos na praia; f) Micuçu é encontrado e leva um tiro na cabeça; g) Micuçu escuta um bebê chorando e um vira-lata latindo; h) Micuçu morre; i) no dia seguinte, novamente procuram outro foragido; e j) a história não tem fim. A percepção desses detalhes foi excepcional para gerar uma discussão profícua na sala de aula com todos os alunos. Fatores sociais, principalmente de classe e raça, e culturais foram abordados, fazendo com que ficassem atentos à fala dos colegas e relatassem acontecimentos de ordem pessoal vivenciados em seus bairros, que se assemelhavam aos acontecimentos relatados no poema. É importante assinalar que, neste momento, os alunos não se ativeram apenas ao enredo do poema, mas colaboraram com questões externas a ele, ou seja, eles produziram reflexões culturais, sociais e interculturais. Houve um engajamento muito grande do grupo com o texto e o contexto apresentados.

Após as leituras e discussões das etapas anteriores, foi proposto na etapa iv), a partir da percepção do caráter cíclico do poema, que criassem uma continuação para o poema. Os alunos deveriam escrever individualmente uma ou duas estrofes de maneira livre, para acrescentar ao texto traduzido, uma vez que a produção foi feita em língua portuguesa, visto que os aprendizes ainda não se sentiam confortáveis para escrever em língua inglesa e não havia tempo suficiente para executar um trabalho linguístico mais aprofundado. Feito isso, 


\section{ITHenapius REFLECTIONIS}

Revista Eletrônica de Graduação e Pós-Graduação em Educaçäo

aqueles que se sentissem à vontade poderiam compartilhar com o restante da turma a sua produção. Seguem algumas produções dos alunos apresentadas nos quadros 1, 2 e 3 :

\begin{tabular}{|c|c|c|}
\hline Quadro 1 & Quadro 2 & Quadro 3 \\
\hline $\begin{array}{l}\text { Estrofe } 1 \\
\text { Olhei para o céu e via estrelas } \\
\text { Olhei para o chão, só bala de } \\
\text { oitão } \\
\text { Quando vejo um inocente } \\
\text { A beira de um caixão }\end{array}$ & $\begin{array}{l}\text { Estrofe } 1 \\
\text { Mas esse ladrão } \\
\text { era diferente. } \\
\text { Branco da burguesia } \\
\text { Tratado como freguesia. }\end{array}$ & $\begin{array}{l}\text { Estrofe } 1 \\
\text { Micuçu foi realmente } \\
\text { Uma pessoa "anormal", mas } \\
\text { isso } \\
\text { Não quer dizer que todo negro } \\
\text { E pobre seja igual. }\end{array}$ \\
\hline $\begin{array}{l}\text { Estrofe } 2 \\
\text { O rico cantando, o pobre } \\
\text { chorando } \\
\text { Na janela da mansão, e o pobre } \\
\text { no lajão } \\
\text { O menor no tráfico em busca } \\
\text { dos trocados } \\
\text { O menor chorando e o rico } \\
\text { pouco se importando } \\
\text { "Ele era funkeiro mais era pai } \\
\text { de família" (cultura do funk) }\end{array}$ & $\begin{array}{l}\text { Estrofe } 2 \\
\text { Não foi morto, nem preso } \\
\text { Só Micuçu que era preto } \\
\text { Sua tia ainda chora } \\
\text { Por fora viva, por dentro } \\
\text { morta. }\end{array}$ & $\begin{array}{l}\text { Estrofe } 2 \\
\text { Mais outro contexto torto } \\
\text { É que bandido bom é bandido } \\
\text { morto } \\
\text { Não sei como essa ideia nasceu } \\
\text { Mas tá aí uma grande prova que } \\
\text { o } \\
\text { Preconceito não morreu. }\end{array}$ \\
\hline
\end{tabular}

As estrofes mostradas no Quadro 1 nos leva a inferir que o aluno que produziu o texto reconhece as diferenças existentes na sociedade brasileira e no tratamento dado às pessoas que vivem nas comunidades mais pobres. Na primeira estrofe, podemos perceber como o aluno descreve o contexto cotidiano da vida nas comunidades de uma grande cidade, como a da Babilônia, no Rio de Janeiro. Na segunda estrofe, nota-se, de forma mais clara, o reconhecimento por parte dele do contraste social construído no poema, ou seja, o aluno buscou manter a temática abordada e discutida na etapa anterior. Esse contraste foi construído por meio das seguintes palavras opostas: rico / pobre; cantar / chorar; e mansão / lajão. Os ricos cantam - estão afastados da fome, da violência e da morte existentes nas comunidades -, moram em mansões, não frequentam lajões. Os pobres, ao contrário dos ricos, choram - estão expostos a todas as mazelas sociais e são marginalizados socialmente. $\mathrm{O}$ desfecho do poema indica, mais uma vez, a consciência social que o aluno tem sobre a estigmatização sofrida por determinados grupos sociais e suas culturas pois, evoca um trecho do funk "Rap do Silva", composto por MC Bob Rum, que relata a morte de um funkeiro que 


\section{ITINPARINS REFLETIONIS}

Revista Eletrônica de Graduação e Pós-Graduação em Educaçäo

era um homem honesto. Assim, o poema faz uma ponte entre duas realidades brasileiras, a de Micuçu, apresentada no poema, e a dos Silva, conhecimento prévio do aluno.

No Quadro 2, a aluna, em sua produção abarca não apenas a questão das diferenças entre classes, mas introduz outras duas temáticas: o racismo vivido pelos negros e os privilégios dos brancos, principalmente, os burgueses. A cor da pele e a classe social definem, nas estrofes adicionadas ao poema, o destino que cada sujeito terá. Portanto, o poema ilustra a realidade social dos negros e pobres no Brasil. Na primeira estrofe, ela enfatiza a singularidade de Micuçu, como um ladrão diferente, mas também o contraste da relação social com o ladrão branco. Na segunda estrofe, ela explora o fato de que Micuçu, por ser negro, sofre as consequências sociais de seus atos, morte ou prisão, e que o branco não tem o mesmo destino, nada acontece a ele. No fim, quando afirma a condição da tia após a morte de Micuçu, ela relembra que "vidas negras importam". O tom de denúncia desemboca no apontamento da desumanização histórica sofrida pelos sujeitos negros, bem como, a resistência das comunidades e de seus habitantes.

Por fim, as estrofes mostradas no Quadro 3, revelam que o aluno reconhece as falhas cometidas por Micuçu, mas também associa a generalização dos atos para todo o grupo com a perpetuação do racismo e preconceito. Na primeira estrofe, ele reforça o não enquadramento de comportamento de Micuçu, mas alerta que esse comportamento não pode ser generalizado a todo negro ou pobre. É interessante ressaltar a utilização das aspas quando se pretende descrever o ladrão da Babilônia nessa estrofe. Essa utilização pode indicar um lastro de memória que aponta para uma "anormalidade" como fruto de um efeito social. As circunstâncias (sociais) prováveis a que Micuçu foi exposto podem ter colaborado com suas atitudes. A generalização ainda é combatida na segunda estrofe quando o aluno chama atenção de que os sujeitos negros e pobres das comunidades não são bandidos. Ele relaciona essa visão social à ideia de que "bandido bom é bandido morto", denunciando a existência de preconceito e racismo e a sua propagação.

A execução das etapas nas aulas reforçou a ideia de que, como sinalizado por Wąsikiewicz-Firlej (2012), a literatura é capaz de envolver os aprendizes cognitiva e emocionalmente, proporcionando um bom desempenho e atraindo a atenção de todos. Dessa forma, o uso do texto literário, tendo em vista que este é um material autêntico, como enfatizou Bozza e Calixto (2013), tem a potencialidade de extrapolar o conteúdo puramente linguístico e ir ao encontro da subjetividade dos alunos. As produções escritas, resultantes da 


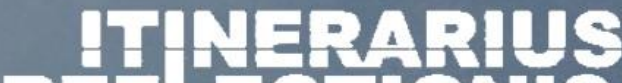 REFLETIONIS}

Revista Eletrônica de Graduação e Pós-Graduação em Educaçäo

última etapa, demonstraram a forma como os alunos interagiram com o poema, testificando que houve uma troca de vivências e, de certo modo, uma identificação entre essas vivências, ou seja, como pontua Corchs (2006), os alunos elaboraram o conhecimento novo produzindo reflexões sobre suas realidades. A junção entre os conhecimentos prévios dos alunos e as significações atribuídas ao poema, gerou um bom engajamento na proposta de produção textual, dentro da abordagem intercultural, defendida por França e Santos (2008). Além disso, como sugere os documentos oficiais, estas produções exemplificam o papel essencial do professor como promotor e facilitador do letramento literário, segundo apontou Cosson (2014) e Souza e Cosson (2011). Portanto, o poema foi um instrumento fundamental para a experiência de uma aula intercultural, que não somente foi produtiva no que diz respeito aos objetivos de uma aula de língua inglesa, como também transformou, de maneira significante, o modo como os alunos percebem a literatura como promotora de reflexão e expressão do seu meio social.

\section{CONSIDERAÇÕES FINAIS}

O presente estudo se pautou na proposta de trabalhar durante o último estágio supervisionado de língua inglesa do curso de Licenciatura em Letras Português/Inglês e suas Literaturas, direcionando às literaturas de língua inglesa, em duas aulas do ensino médio em uma escola da rede pública de Lavras, o poema "The Burglar of Babylon" (1965), da poeta estadunidense Elizabeth Bishop, como ferramenta de estímulo no processo de ensino e aprendizagem da língua inglesa, compreendendo que sua utilização pode e deve ser explorada para além do propósito puramente linguístico. As aulas foram organizadas em quatro etapas, que podem ser divididas da seguinte forma: i) informações sobre a autora e o contexto de produção do poema; ii) leitura, em voz alta, do poema no original e entendimento geral; iii) leitura da tradução do texto em português e discussão mais aprofundada sobre a temática escolhida; e iv) produção textual, em língua portuguesa, da continuação do poema, como forma de acrescentar ideias ao que foi inicialmente criado pela poeta.

A análise indicou que os aprendizes que, no início da primeira aula, afirmaram não ter interesse em literatura, de maneira geral, se engajaram na atividade com base no texto literário de língua inglesa proposto, participando de forma efetiva de todas as etapas e contrariando a ideia de que literatura seja chata ou irrelevante. Eles estabeleceram pontes de 


\section{ITHepapins REFLECTIONIS}

Revista Eletrônica de Graduação e Pós-Graduação em Educaçäo

diálogos entre o texto literário e as vivências de ordem pessoal e social. Nesse sentido, o trabalho demonstrou que as literaturas de língua inglesa podem, de fato contribuir com a formação crítica dos cidadãos, além de promover uma educação de ordem intercultural e de servir como material autêntico. Questões de classe e raça foram encontradas nas produções realizadas pela turma, o que demonstrou que a obra literária auxilia na denúncia de aspectos sociais e aproxima a literatura da realidade desses sujeitos. Assim, os objetivos de expor os alunos ao texto literário no original, de promover a interação entre os alunos com o texto e de criar abertura para que, posteriormente, haja um interesse pela aprendizagem da língua foram atendidos na proposta de aula analisada.

Portanto, este estudo possibilitou reforçar a ideia de que o uso de textos literários de língua inglesa pode servir de instrumento para instigar os aprendizes a se interessarem pela cultura, pela leitura e pela aprendizagem de língua inglesa, a partir da identificação cultural e social e pelo diálogo intercultural que podem ser explorados nos textos literários. Assim, a literatura e o letramento literário trazem benefícios variados para a sala de aula e atendem aos aspectos apresentados por documentos oficiais como a BNCC.

\section{REFERÊNCIAS}

BOZZA, Morgana C.; CALIXTO, Benedito. "A importância do texto literário nas aulas de língua inglesa no ensino médio". Portal Dia a Dia Educação (Seed-PR). Disponível em: http://www.diaadiaeducacao.pr.gov.br/portals/pde/arquivos/809-4.pdf. Acesso em: 30 mar. 2019.

BRASIL. Ministério da Educação. Secretaria da Educação Básica. Base Nacional Comum Curricular (BNCC). Brasília, DF, 2017. Disponível em: http://basenacionalcomum.mec.gov.br/\#/site/inicio. Acesso em: 3 dez. 2018.

COLLIE, Joanne; SLATER, Stephen. Literature in the language classroom. Cambridge: Cambridge University Press, 2001.

CORCHS, Margareth. O Uso de Textos Literários no Ensino de Língua Inglesa.

Dissertação de Mestrado Acadêmico em Lingüística Aplicada. Universidade Estadual do Ceará (UECE), 2006. Disponível em:

http://www.uece.br/posla/dmdocuments/MargaretCorchs.pdf. Acesso em: 20 mar. 2019.

COSSON, Rildo. Letramento Literário. In: Glossário Ceale. Disponível em: http://ceale.fae.ufmg.br/app/webroot/glossarioceale/verbetes/letramento-literario. Acesso em: 15 ago. 2019. 


\section{ITHepapins REFLETIONIS}

Revista Eletrônica de Graduação e Pós-Graduação em Educaçäo

FRANÇA, Oldinê R. de; SANTOS, Cynthia A. B. dos. "Visão e abordagem cultural de professores em sala de aula de LE e os PCNs". Revista Horizontes de Lingüística Aplicada, vol. 7, n. 2, p. 80-97, 2008.

LAKATOS, Eva M.; MARCONI, Marina de A. Metodologia Científica. São Paulo: Atlas, 1991.

LAZAR, Gillian. Literature and language teaching: a guide for teachers and trainers. Cambridge: Cambridge University Press, 2009.

SILVA, Luciana S. da. "O ensino de língua inglesa através da literatura: possibilidades para as aulas do ensino fundamental e médio". Revista Porto das Letras, vol. 2, n. especial, p. 196-213, 2016.

SOUZA, Renata J. de; COSSON, Rildo. "Letramento literário: uma proposta para a sala de aula". Acervo Digital da UNESP. 2011, p. 101-107. Disponível em:

https://acervodigital.unesp.br/bitstream/123456789/40143/1/01d16t08.pdf. Acesso em: 25 mar. 2019.

WĄSIKIEWICZ-FIRLEJ, Emilia. "Developing cultural awareness through reading literary texts". 2012, p. 03-15. Disponível em:

https://taikomojikalbotyra.lt/ojs/index.php/taikomoji-kalbotyra/article/download/10/11/. Acesso em: 19 nov. 2018.

ZYNGIER, Sonia. "O lúdico, o imaginário e o pragmático no ensino de literatura". Revista Fragmentos, Santa Catarina, vol. 22, n. 2, 2011. Disponível em:

https://periodicos.ufsc.br/index.php/fragmentos/article/view/6000/5549. Acesso em: 25 mar. 2019. 